\title{
O CARÁTER EFÊMERO DA OBRA DE ARTE PERMANENTE OU A EFEMERIDADE DO PERMANENTE NA OBRA DE ARTE
}

\author{
Odone José de Quadros*
}

SÍNTESE - a característica adorniana de fogo de artificio revelada pela produção artística moderno-contemporânea é própria de todas as obras de arte de qualquer época. A permanência do fato artístico estará entregue à sua ordem de leitura e execução no tempo. Serão apresentadas as caracteristicas da razão dominadora, o ponto de vista do Ersatz, a leitura da obra como execução e como recepção.

\begin{abstract}
- the adomian fireworks characteristic revealed by the moderncontemporary artistic production is own of all the works of art of any time. The permanence of the artistic fact will be given its reading order and execution in the time. The characteristics of the dominant reason will be presented, the point of view of Ersatz, the reading of the work as execution and as reception.
\end{abstract}

\section{1 - Preliminares: o fogo de artificio}

Pretendo, aqui, examinar o aspecto da momentaneidade, quase constante happening da produção artística moderno-contemporânea, aspecto este sublinhado, sobretudo, nas análises dos textos de Adorno ${ }^{1} \mathrm{~A}$ imagem do fogo de artifício atribuída à obra artística, dá bem esta dimensão. ${ }^{2}$ Assim como a analogia do arcoíris. ${ }^{3} \mathrm{E}$ procurar mostrar que esta momentaneidade não é característica só da arte moderna e contemporânea, mas que é própria de toda a produção artística de todos os tempos, portanto, também daquela obra dita permanente, pela tradição.

* Professor na Pontificia Universidade Católica do Rio Grande do Sul, PUCRS.

1 ADORNO, Theodor W. Teoria estética. São Paulo: Martins Fontes Editora, 1970. "Se a apparition é o que se ilumina, o palpável, então a imagem é a tentativa paradoxal de conjurar o que há de mais efêmero. Nas obras de arte, trar.scende-se algo de momentâneo; a objetivação faz da obra artística um instante" (p. 102).

2 Id. ibid., p 98. "O fenômeno do fogo de artificio que, por causa do seu caráter efêmero e enquanto divertimento vazio, dificilmente foi julgado digno de consideração teórica, é prototípico para as obras de arte $[\ldots]$ o isolamento da esfera estética na total gratuidade de um efêmero absoluto não pode servir-lhe de definição formal. Não è pela perfeição elevada que as obras de arte se separam do ente indigente mas, de modo semelhante ao fogo de artificio, ao atualizarem-se numa aparição expressiva fulgurante."

3 Id. ibid. "Quem se contenta com compreender algo na arte transforma-a em evidência, o que ela de modo algum é. Se alguém procura aproximar-se de um arco-iris, ele esvanece-se” (p. 142). 
Dado que, na tradição, sobretudo aquela da obra de arte bela, analisada por Hegel, ${ }^{4}$ as obras de arte se explicavam ou a partir da soberania do espirito sobre as coisas, da preferência do conceito sobre a produção, ou da adequação ou inadequação entre produção artística e sua justificação teórica, às obras se lhes eram aplicadas notas constitutivas essenciais, o que lhes conferia um caráter paradigmático de exemplaridade permanente. O valor estético, fundado no horizonte teórico, tornava a obra continente de um valor absoluto, especificando-a para além e para fora das produções comuns da vida, emprestando-lhe um caráter solar. À obra correspondente ao ideal do belo se lhe era garantida a atemporalidade, a acronologia. Aquilo que fosse sancionado pela razão como produção bela, era preferenciado na ordem da produção ou da poiesis.

Com a modernidade, com a perda do ideal do belo, com o fim da arte bela, um tipo de razão "administradora" se impôs. A correspondência entre o momento teórico e a produção se rompe, estabelece-se um hiato entre a razão instrumental moderna e o fazer poiético. Daí resultou um certo desamparo teórico frente às artes modernas.

Carente da fundamentação teórica tradicional, a produção artística mais recente parece ter perdido a consistência do permanente, do valor perene e constatável, comprovável e argumentável. Da exemplaridade passou a um inafastável incômodo para a razão moderna instalada: um enigma ${ }^{5}$ necessário e não descartável. Não mais permanentes, não mais detentoras de valor absoluto cujo fundamento era teórico, as obras poiéticas, hoje, aparentam realmente qualidades próprias dos fogos de artifício.

Este trabalho pretende afirmar e, para isto, buscar fundamento, que toda a obra de arte, seja também aquela dita ou tida como permanente, só acontece como evento efêmero.

Ou seja, em que medida e em que sentido é próprio de toda a produção artística 0 aspecto passageiro, fugaz, momentâneo.

Como tenho a eleição de um tema para o meu trabalho de doutorado, a partir de um autor, no caso, o filósofo italiano Luigi Pareyson, não me furtarei de adotar pontos de vista expedidos pelo autor citado, constantes em bibliografia referida ao final.

A busca de fundamentação ou das condições de possibilidade para tal afirmativa terá duas vertentes: a da concepção de leitura e execução da obra, dentro do contexto da interpretação em Luigi Pareyson e o da obra como portadora de lacunas, potencialidades a serem preenchidas pelo intérprete, no contexto da estética da recepção.

O pressuposto presente como horizonte deste ensaio é o de que a obra de arte moderna, pondo-se como fato autônomo e independente em si mesmo, em relação ao desamparo em que deixa a razão domesticadora e apropriadora, delimita para si também seu valor de temporalidade. Poder-se-ia dizer que a sua duração não está

4 HEGEL, Georg Wilhelm F. Estética. Lisboa: Lisboa Guimarães Editora, 1962-1964-1972-1993. - Aesthetik. Frankfurt: GmbH, 1960. — . Einleitung in die Aesthetik. München: W. Fink, 1967.

5 ADORNO, W., id. ibid., p 140. "Todas as obras de arte, e a arte em geral, são enigmas; isso desde sempre irritou a teoria da arte". 
adstrita ao seu tempo de existência, embora seu tempo de existência possa ter uma duração.

Isto nos vai colocar de início algumas questões: o que se quer entender por permanente; em que sentido uma obra pode ser dita ou tida como permanente e em que sentido uma obra pode durar para além do seu tempo de existência?

Entender-se por permanente simplesmente o fato de que a obra de arte, nascida no tempo, com as marcas daquele tempo, ultrapassa todos os tempos, pode restringir a questão à esfera de um problema meramente cronológico, de um antes e um depois. Ou pode cair na afirmação do valor paradigmático de cada obra que a arranca do genérico e a põe na ordem do para sempre. Assim, as obras de arte seriam duradouras porque e quando "verdadeiras" obras de arte e, como tais, reconhecidas. Neste caso, a qualidade de duradouras seria também sintoma de "veracidade" da obra. A categoria tempo teria um caráter sancionador. Por que, o que é que estas obras teriam que as fariam atravessar os tempos, as épocas, as culturas; que thes conferiria uma história sem cronologia; que pareceriam realizar um recôndito desejo do homem: o de ir para além do tempo?

Bem diferente do entender-se o permanente da obra de arte em relação a um conceito ao qual ela se referencia. Neste caso, as obras seriam ditas permanentes porque condizentes com o conceito, com o ideal que as explica e lhes dá razão de ser. Assim, permanecendo a relação entre uma determinada produtividade artística com um conceito ao qual esta produtividade está adequada, aquele conjunto de obras simplesmente permanece por uma permanência relacional entre as obras e seu conceito. Ou seja, aqui, permanente não significa, em primeiro lugar, uma duração no tempo meramente cronológico, mas uma permanência relacional depositada na vigência sustentada da adequabilidade das obras ao horizonte conceitual que as referencia. Portanto, neste sentido, a permanência não é, em primeiro lugar, a das obras mesmas, mas antes a permanência de uma relação adequada. Uma coisa assim como a história da arte é uma história sem cronologia, ou o tempo da arte é um tempo sem tempo porque a duração entre uma determinada manifestação de produtividade artística e o aparato teórico-conceitual que a sustenta e explica são ainda reconhecidos no tempo.

Para os fins deste ensaio, vamos tomar o caráter permanente no segundo sentido apresentado: o da permanência relacional, isto é, da vigência, no tempo, de uma reconhecida adequação entre um tipo de produtividade artística e o seu referencial teórico.

Por isso, poderia haver comprazimento, hoje, por exemplo, diante do retrato de Baldassare Castiglione, pintado no 1500 por Rafael ou na audição do romântico poema sinfônico "O Moldau" de Bedrich Smetana. São exemplos de obras, perante as quais, o intérprete nunca estaria ao desamparo, porque correspondentes sempre a alguma vertente implícita ou não dos momentos teóricos do ser humano que se fizeram presentes epocalmente e que se teriam concretizado, por assim dizer, em obras, fatos artísticos.

Esta não é porém a situação da produção artistica moderna. A inadequação é que tem vigência. A tensão entre a experiência estética e o conhecimento teórico projetado num tipo de história, de sociedade e de razão é o que está acontecendo. 
A arte moderna se tematiza ela própria a si mesma e, por isso "as obras de arte não devem ser compreendidas pela estética como objetos hermenêuticos; na situação atual, haveria que apreender a sua ininteligibilidade". ${ }^{6}$ Porque "a arte não pode satisfazer o seu conceito"?

\section{2 - A razão do "mundo administrado"}

A razão científico-técnica é a justificadora do indivíduo e da sociedade esquartejados. Esquartejados pela hipertrofia de uma face da razão e pelo sufocamento da unitotalidade das operações da pessoa. Onde quer que a modernidade tenha espalhado suas crises de carência de legitimidade, este tipo de racionalidade se estabelece e através de um discurso técnico, cria, em cada caso, uma estrutura de poder e de linguagem interesseiros. Este discurso técnico interesseiro e dominador se projeta sob a ficção de ser neutro, substancialmente objetivo, avalorativo, não ideológico, diante do qual não se podem ter nem suspeitas, nem dúvidas: ele é apodíctico. É um discurso que incorpora cada vez mais em si as técnicas de uma vida burocrática mercenária que, por sua vez, constrói um discurso ideológico que regula e comanda tudo na sociedade: as representações, as avaliações, as necessidades. A razão científico-técnica é um tipo de razão tão pérfido que inventou um discurso mascarante que esconde sempre um subentendido que precisa ser desmistificado, porque ele mesmo se põe os seus próprios princípios de legitimação. É a razão-parte travestida de razão-todo.

É fácil detectar os sintomas do "mundo administrado": caracteriza-se pelo predomínio de uma concepção produtivista, de competitividade, de uma gerência da competência e da eficiência segundo os critérios deste tipo de razão instrumental; pelo respeito, pela admiração e pela consagração da força e do domínio de tudo o que emana desta ideologia; da exaltação da idéia de "progresso" que passa a ser sinônimo de distribuição e consumo, da idéia de classes sociais, de escalas sociais, de ascensão; a aceitação enfim de um pragmatismo cuja única regra é a funcionalidade e a eficiência: funciona? Dá certo? Vamos em frente! É isso que interessa.

$\mathrm{E}$ assim, ela, a razão científico-técnica da modernidade, é a responsável pela produção de um sentido social ou do sentido social vigente. Um sentido unidimensional que desterrou de suas fronteiras todo o tipo de valoração ética e de sentimento. É a prova de seu caráter totalitário e opressor. "La rationalité technologique ne met pas en cause la légitimité de la domination, elle défend plutôt, l'horizont instrumentaliste de la raison qui s'ouvre sur une société rationalement totalitaire."” Razão reificante. Afã de poder.

Outro sintoma agudo da modernidade é o individualismo. $O$ período moderno forjou uma forma histórica de sociabilidade onde o ápice acontece com o surgimento do indivíduo livre. Indivíduo, agora, não exatamente por constituição, mas por eleição. Seu destino não está mais fora dele, não lhe é determinado prévia ou

\footnotetext{
Id. ibid., p. 138.

Id. ibid., p. 69.

MARCUSE, H. L'homme unidimensionnel. Paris: Minuit, 1968, p. 34.
} 
externamente. Indivíduo, senhor de sua história, isto é, do seu tempo: do seu antes, do seu agora e do seu depois. E o passado e o futuro, em suas mãos, no presente.

Só que esse indivíduo, logo se dá conta de que a sua história, tão única e tão irrepetível, tem um tempo delimitado: o curto espaço de sua própria existência. Então, toda esta individualidade, toda esta liberdade, esta eleição, só pode ser construída no processo de construção de seu parco tempo de vida.

$O$ destino não lhe vem de fora, mas, de fora lhe vem uma pré-determinação, um limite: o tempo é o de sua duração - a finitude.

Por isso, o inđivíduo moderno é um indivíduo cujo núcleo de vida converge fortemente para o significado da morte. $\mathrm{O}$ indivíduo do mundo moderno secularizado trocou o antigo marco da eternidade pelo da finitude.

O momento presente se avulta e impõe uma necessidade: de que seja vivido integralmente. Com acontecimentos e obras. Com realizações, ao máximo.

No entanto, o indivíduo da modernidade não se sente centrado. Neste sentido, Max Weber afirmou que "no mundo modemo, os seres humanos podem sentir-se fartos, esgotados ou cansados da vida, nunca plenos dela". ${ }^{9}$

O ser humano da modernidade, no entanto, é menos indivíduo pela sua unicidade ou pela sua decisão, e mais, pela inépcia e aversão ao nós. Ele é arredio ao que é comunitário, coletivo, comum: se esquiva da participação. Sua vida, sua morte, seu tempo limitado, suas realizações é que estão em jogo. Se for preciso, ele é até desonesto para não perder as oportunidades espremidas nessa temporalidade tão curta.

Ele não vive como uma tartaruga das Galápagos. Ele não tem quatrocentos anos pela frente. Muito antes, ele se assemelha aos andróides replicantes do filme Blade Runner que sabiam que haviam sido programados para durar quatro anos. Por isso, destituídos de memória e de sentimento. Não tinham passado, nem futuro. Eram um presente de nada.

Que fisionomia isto dá para o individuo moderno?

"Em conseqüência, a vivência do momento presente, para grande parte dos homens e mulheres contemporâneos, antes de possibilitar a percepção de si como seres completos, indivíduos na extensão do termo, fá-los sentirem-se como seres desconectados, sem raizes e sem perspectivas." ${ }^{10} \mathrm{~A}$ importância do agora instaura o império do efêmero e nem o passado e nem o futuro escapam, e acabam su sumindo, tal o fulgor do presente.

"Disto decorre - uma vez que se perdeu o sentido do pertencimento, de part:cipação em um 'nós'- que, hoje, para a maioria das pessoas, a tradução subjetiva da significação da autonomia individual e da realidade que a sustenta é um profundo individualismo em que cada um se volta egoisticamente para seus desejos e expectativas e não reconhece no outro um semelhante. $O$ resultado desse processo não é senão o crescimento contínuo do consumo e do lazer, tomados fins em si

9 Tempo Social - Revista de Sociologia da USP, v. 6, n. 1 e 2, jun. 1995, p. 96, artigo "O moderno e o contemporâneo: reflexões sobre os conceitos de individuo, tempo e morte" de Maria Helena Oliva Augusto, professora de Sociologia, USP (Max Weber, 1958).

10

Tempo Social, id. ibid, p. 97. 
mesmos, a fragmentação da vida num conjunto de atos sem sentido e a extrema solidão que persegue as pessoas, ainda que vivam em sociedade."11

O indivíduo da modernidade está centrado, sim, mas no quanto ele pode ser eficiente na construção do próprio destino.

Nos primórdios da modernidade, o homem acreditava na idéia da humanidade construindo seu próprio destino, na possibilidade de um conhecimento total e na perspectiva de dominar por inteiro a natureza. A modernidade do homem contemporâneo, porém, perdeu todo este "romantismo" e se afoga em uma linearidade do tempo: é hora do quantitativo em detrimento do qualitativo. É tempo de ser utilitarista. É preciso ser eficiente, logo, depressa, porque o tempo está passando. Na estética, esta atitude da subjetividade imperante põe como cânone a satisfação, o prazer: "Obedecendo às legalidades subjetivas sem consideração pelo seu outro, mantém, sem ser abalado por um qualquer outro, o seu caráter de satisfação: a subjetividade, inconsciente de si mesma, saboreia o sentimento da sua dominação."12

Oconre, então, um paradoxo. $\mathrm{O}$ individuo da modernidade atual que se projetava indivíduo, sobretudo pela escolha de engendrar seu próprio destino, se vê empurrado pelo ritmo externo. Ele que estava tão seguro no seu reduto, que vivia como se houvesse um muro invisivel entre ele e os outros, passa a ser dominado e a se sentir vitima das forças das circunstâncias que nem sabe de onde vêm e nem como controlá-las. Já não constrói mais sua vida, nem seu mundo: não é mais senhor do seu tempo.

E, agora? Separado, fragmentado, atomizado e... desamparado: na solidão.

O sentido que o indivíduo da modernidade de hoje pensava ter para a sua existência, escorreu para fora de si, e ele já tende a achar a vida humana um absurdo mesmo.

Mas, como é que se pode falar de sentido, na individualidade separada? Exatamente, o sentido não é uma categoria que supõe "ser-com"? O sentido não é algo que se possa encontrar nem no indivíduo separado, murado, nem se depreender de elocubração universal. O sentido humano vive e respira dentro da categoria solidariedade, generosidade, alteridade. 0 sentido não é próprio do sujeito e sim da pessoa. O sentido individual só é pelo sentido social e vice-versa, embora o fundamento seja sempre a pessoa.

Por isso, para o indivíduo da modernidade atual, a vida e a morte são vividas, carentes de sentido.

A cara do indivíduo da modernidade contemporânea é a cara do "desbussolado", sem bússola.

"[...] ao invés do indivíduo autônomo, o que sucede em decorrência dessa forma de estar no mundo, é a perda pelas pessoas dos seus pontos de referência, ao lado da manifestação de um conformismo generalizado. Por outro lado, a possibilidade de regerem sua própria vida, de proverem seu próprio futuro e o de seus filhos, de deixarem marcas duradouras de sua passagem pelo mundo, fica cada

11 Id. ibid., p. 97.

12 ADORNO, W. Op. cit., p. 62. 
vez mais distante para as pessoas. Em suas vidas prevalece a insegurança, a incapacidade de prever o dia de amanhã"13

O que resta? Deixar rolar! Deixar a vida correr. Tudo o contrário do senhor que tem nas mãos as rédeas do seu próprio destino. $\mathrm{E}$, se possivel, esquecer a morte. Virar tartaruga das Galápagos!

O individuo da modernidade contemporânea, porque de cultura secularizada e cientificista, nem da ciência retira conforto. Os meios para prolongar a vida estão aí, mas o indivíduo moderno se sente tão distante da vida.

Dentro deste quadro, a própria "morte se retira para o silêncio dos hospitais e aparece como um momento solitário e vergonhoso."14

Interessante notar a observação apresentada por Lipovetsky. Para este autor, "o ressurgimento das espiritualidades e esoterismos de todo o tipo não é antinômico com a lógica principal de nosso tempo; antes, é uma forma de realizá-la, "permitindo um coquetel individualista de realização". ${ }^{15}$

Interessante se notar, por isto, que a razão dominadora impera num i...pério do efêmero. E, nisto, ainda que a produção artística não possa retirar de nenhum elemento da sociedade a sua explicação, o seu conteúdo semântico, no entanto, ela, a obra, presentificando a ideologia da sociedade na qual surge, não se explica por esta mesma ideologia, ao invés, a provoca e desinstala. E, contudo, leva as marcas desta sociedade.

\section{3-A "Teoria" do Ersatz}

Hoje, numa sociedade da reprodução industrial e do consumo, os defensores do Ersatz, tentando aliar uma forma de historicismo com a necessidade de adequação entre a arte e a explicação que dela se faz, apresentam seu ponto de vista através de um viés preferencialmente sociológico.

Se a sociedade mudou e se há que apresentar uma explicação para os fatos artísticos, que seja um conceito condizente e decorrente desta nova figura da situação social. Deparamo-nos assim com os "teóricos" do Ersatz e com a reivindicação de que é necessário encontrar um novo conceito de arte que corresponda às características da sociedade atual.

Luigi Pareyson, na obra Conversazioni di Estetica, ${ }^{16}$ onde cada capitulo é um artigo sobre temática diversa, aborda esta perspectiva do Ersatz. ${ }^{17}$

O novo conceito de arte deveria atender e corresponder a uma época onde tudo está sujeito ao desgaste de um consumo sempre mais rápido e obrigante. Os ligames entre arte e sociedade parecem sugerir tal novo conceito. Uma sociedade que se caracteriza pelo progresso e incremento da técnica na produção industrial; uma sociedade dos meios de comunicação e de meios artísticos de grande difusão como o rádio, televisão, discos, cinema; uma sociedade onde se desenvolve $o$

13 Tempo Social - Revista de Sociologia da USP. Id. ibid., p 100 (Horkheimer, 1976, p. 168-169).

14 Id. ibid., p. 101.

15 Id. ibid., p. 102 (Lipovetsky, 1988, p. 119).

16 PAREYSON. L. Conversazioni di estetica. Milano: U. Mursia \& C., 1966.

17 QUADROS, Odone José de. Estética da vida, da arte, da natureza. 2. ed. Porto Alegre: Acadêmica, 1986, p. 157-158. 
industrial design e na qual predomina, mais e mais, o emprego sempre mais maciço e industrializado dos mass media.

Que conceito novo atenderia a tais solicitações da sociedade consumista contemporânea? Que caracteres deveriam ornar esta nova concepção de arte?

Só uma concepção de arte que tivesse as marcas desta época, onde tudo é efêmero e passageiro, na ânsia e na pressa voraz de ser substituido por algo diferente. Uma arte consumida no momento. $\mathrm{E}$ que se desgasta junto com a própria vida, o tempo e a época. Mudança.

Uma concepção de arte de mais largo raio de alcance. Não importa que seja "de mais baixo nível". Que não seja perene. Que não seja universal. Que não tenha caráter absoluto. Pois nada, em tal sociedade, de fato, tem caráter absoluto. Só a mudança, o desgaste, o diferente, o efêmero.

Uma concepção de arte mais presente. Que seja reconhecida e que dure até o desgaste. Depois, com a mudança das linguagens, virá nova expressão. Pois, em tal sociedade, a expressão substitui a aspiração. O fato substitui o valor.

Uma concepção de arte mais extensa e não mais confinada a um exíguo número de obras raras e excepcionais, frutos de particulares êxitos e culminâncias. Requer-se agora uma arte presente em todos os aspectos da vida. Uma canção popular, uma propaganda comercial, uma fotografia, um produto de artesanato, qualquer bordado, tudo, tudo poderia ser e seria arte.

Assim, dentro do contexto da busca de adequação entre conceito e arte, surge e se instala uma concepção de arte, vista então como relativista e historicista, sob a alegação de que, se a arte está ligada à vida de onde nasce e brota, deve seguir os mesmos destinos desta.

Parece que o principal problema do Ersatz é o de se ter ainda colocado na moldura de uma adequação: no caso, transpondo a adequação arte e conceito para arte e sociedade. Assim pôde ficar na mira da crítica dos defensores da adequação arte e conceito. Dos que julgam ter o saber e a definição de uma arte específica e própria e que se sentem autorizados, por isso, a simplesmente taxar o ponto de vista do Ersatz como um desvio de quem pretende alçar o genérico, comum e ordinário, ao nivel do específico, incomum, extraordinário.

No entanto, o Ersatz aponta para alguns aspectos muito importantes: a arte está enraizada na vida; o caráter estético e artístico inere a todo o fazer humano e, só por isto, a contínua possibilidade da emergência da arte; a arte é para todos e, neste sentido, popular. Não afastada, não elitizada, não mercadoria no sentido do mercado ideologizado pela produção/consumo. Não obstante, efêmera, momentânea, mutante.

Desde o ponto de vista do Ersatz, o aspecto efemeridade se aplica à produção artística moderno-contemporânea e se fundamenta na iniludivel relação entre arte e sociedade. Mudando as sociedades, mudariam as concepções de tudo, também a da arte e, se esta é a fisionomia da sociedade atual, a ela deveria corresponder um novo conceito de arte. Efêmera em si mesma, mas com explicação heterônoma: as características do mundo técnico e industrializado com suas novas linguagens. Esta a sua explicação conceitual. 
Sem se desprender do modelo de adequação conceito/produção, ainda assim, - Ersatz põe em evidência o caráter de efemeridade da obra de arte. Claro que ainda se referindo à produção da sociedade moderno-contemporânea de caracteristicas técnico-industriais; sociedade da informatização, dos meios de comunicação de massa e da reprodução - do industrial design.

\section{4- A execução da obra aberta}

Neste item, considerarei a posição pareysoniana ${ }^{18}$ sobre a leitura da obra de arte enquanto execução, na medida em que executar é deixar ser e fazer ser a obra, o que ela é e precisa ser. A necessidade que a obra tem de ser executada, de acontecer, de se realizar.

A leitura da obra de arte - e chame-se assim o acesso às obras de todas as artes e não só àquelas da palavra -, como também a leitura dos fatos, da vida, da natureza, de tudo, é, sem dúvida, um ato bastante complexo.

Trata-se, de fato, de reconstruir a obra na plenitude da sua realidade sensível, de modo a que ela revele, ao mesmo tempo, o seu significado, que é ela mesma, e o seu valor artístico, e se ofereça, assim, a um ato de fruição. Trata-se, enfim, de executar, interpretar e avaliar a obra, só assim tendo a ela acesso, só assim "contemplando-a" e "gozando-a".

Quando se trata da atividade que é a leitura, duas posições sintomáticas estão sintetizadas, dentro do pensamento da cultura italiana, por exemplo, nas concepções opostas de Croce e de Gentile.

Croce afirmando a rievocazione, atitude que descarta toda e qualquer iniciativa pessoal. Nada de iniciativa: nem na iniciativa, pois esta decorre de uma intuição alógica do Espírito Universal; nem no conteúdo, pois que este não é mais do que a representação da obra como ela é.

Gentile defendendo a traduzione, diante da obra que permanece externa realidade muda e inerte e que só é refeita pela vida do espírito vivente do leitor. Por isso, de mil vidas... pode a obra viver.

Portanto, Croce acentuando o caráter de expectante do "leitor" que, passivo, deixa a obra ser. Fidelidade. Gentile dando ênfase ao caráter criativo do intérprete que, ativo, faz a obra ser. Inventividade.

Exatamente porque ao diálogo com a obra só se pode chegar através de um processo, a um tempo receptivo e ativo, procurando o ponto de vista desde o qual olhar a obra. Dialogando com ela numa relação de pergunta e resposta, de perguntas que se souberam fazer e de respostas que se souberam captar, sabendo colocar-se no viés da perspectiva mais reveladora e colhendo, dela, o aspecto mais "falante".

A fruição, ou a apreciação estética da obra, aparece assim como uma conquista, já que ela é quietude só enquanto conclui e, portanto, inclui um processo, não enquanto o apague ou anule, pois ele não alcançará jamais a sua final consumação. Pois a obra de arte é objeto de uma consideração dinâmica para quem

18 PAREYSON, Luigi. Estetica: teoria della formatività. 3. ed. Firenze: G. C. Sansoni S.p.A., 1974 (Prima Edizione - Torino: Biblioteca di Filosofia, 1954. p. 219 a 247). 
souber resgatá-la da sua aparente imobilidade para colhê-la no movimento de onde nasceu. Deixando-a ser e fazendo-a ser como ela é, e como ela quer ser.

Que a leitura e a fruição da obra sejam ativas, aparece, sobretudo, do fato que ler significa executar, e executar significa fazer viver a obra da sua própria vida e torná-la presente na plenitude da sua realidade sensível e de significado.

Semelhantemente à atividade daquele que executa um texto musical ou dramático: executar, nestes casos, é chamar o texto à vida e fazer atuar (ato) a sua realidade originária. Ao executar, o intérprete realiza, dá de novo à obra a realidade que lhe é própria, a faz viver.

Mas, não se pense que este caráter de leitura-execução seja aplicável unicamente ao teatro e à música. É, isto sim, próprio de todas as artes. O preconceito deriva de um equivoco: o de se pensar que a execução verdadeira e própria, ou a realização, se reduza a uma decifração de uma escritura convencional, ou a uma apresentação da obra ao público.

É claro que, tanto na música quanto no teatro - também na poesia - a realização está conexa com uma decifração de uma escritura simbólica - partitura, script -, e com o trabalho de mediação que o intérprete desenvolve entre a obra e o público, mas não se identifica com estas duas operações, embora, com elas, indivisivelmente conexa.

Quando, no entanto, se afirma identidade em vez de indivisibilidade, quando e se se afirma que a execução é essencialmente igual à decifração de uma escritura simbólica e convencional ou à apresentação da obra de arte ao público, ou a estas duas coisas ao mesmo tempo, então a conseqüência é a de que, de fato, a execução seria própria só de algumas artes, não de todas.

Se fosse assim, então se faria importante a distinção entre as artes: entre as que se podem entregar a sinais escritos e as outras que não precisam disto e que estão inteiramente presentes nos seus sinais físicos.

As artes que não precisariam de escritura são, quase sempre, artes visuais, cuja existência artística se identifica completamente com a sua própria existência física que lhes dá consistência e conservação.

Outras, ao contrário, que são essencialmente artes sonoras, possuiriam, por assim dizer, duas distintas existências, uma vez que a conservação de sua existência física implica um meio, semelhantemente à escrita alfabética ou às notas musicais. São, também elas, entregues a uma página escrita ou a um pentagrama. Duas coisas decifráveis mas que não têm, por si mesmas, nenhuma importância estética e artística.

Teriamos, assim, se isto fosse procedente, dois tipos de artes: as necessitantes da decifração: a poesia, a música e o teatro, possuidoras, portanto, de uma existência convencional e convencionada; e as artes, como a pintura e a escultura, para as quais, olhar para o seu aspecto sensivel que as contém inteiramente, já é suficiente. E assim, pareceria que só as primeiras exigem execução.

Acresce ainda que, se executar significasse apresentar uma obra ao público, aumentaria para primeiro plano a distinção entre as artes que conquistam a sua existência e realidade artística somente através de uma mediação entre o público 
e a obra e aquelas que, ao contrário, revelam a sua realidade artística sem a intervenção de mediadores. Ou seja, as obras que necessitassem de mediação necessitariam de execução, as outras não.

Será assim?

Se distinguíssemos o que comumente se chama de "execução" em três diferentes aspectos: a decifração, a mediação e a realização, poderiamos constatar que só o último aspecto, o da realização contém aquilo que é essencial à execuÇão, e que, por isto, diz respeito a todas as artes, indistintamente.

É sabido que existem artes que, muito embora oferecendo-se à vista e não ao ouvido, cujo corpo e realidade artística apresentam-se em seus sinais físicos, são passiveis também de notações convencionais e simbólicas. A arquitetura e a dança são exemplos disto. Entre o arquiteto e a empresa construtora, entre o coreógrafo e o dançarino podem existir uma simbologia gráfica a ser lida ou executada, neste primevo sentido de decifrada.

São até notações convencionais, muitas vezes, que não apresentam a mesma precisão daquelas musicais e literárias, isto especialmente na dança: é um tipo de notação mais aproximativa do que propriamente bem definida. Mas, assim como músicos, poetas, dramaturgos podem apor indicações outras por julgarem freqüentemente insuficientes as notações convencionais, assim também na arquitetura e na dança, não obstante o caráter aproximativo dos sinais convencionais, pode um bom entendedor "ler" a obra ainda não executada, executando-a mentalmente no ato mesmo de decifrar a escritura simbólica. E aqui estamos no limite da distância máxima e mínima entre executar e decifrar.

Mas se persistirmos no exemplo da música e da literatura, certamente "ler" uma obra de arte não significa somente sonorizar os sons e as palavras. Ler uma obra de arte pode também querer dizer "visivisá-la", visualizá-la, ou melhor, torná-la visivel. Assim, por exemplo, a existência de uma pintura no escuro é tão distante da sua existência artística, quanto uma partitura da execução pública musical. A mesma atividade requerida para passar uma partitura à sua realidade artística musical completa - para sonorizá-la, é a atividade requerida para passar uma pintura da escuridão para o modo de olhá-la e de iluminá-la que realiza a pintura e a evidencia em toda a sua realidade artística - para "visivisá-la", ou melhor, visualizá-la.

Nos dois casos, se trata de sonorizar e de "visivisar" - visualizar, no modo querido pela obra mesma, de modo a fazê-la viver como ela mesma quer e precisa viver.

Aí chegamos ao ponto que suscitou nossa indagação sobre o caráter efêmero da obra de arte permanente, ou a efemeridade permanente da obra de arte, de todas as obras de arte, de qualquer época, não só a da moderna.

Porque, se ler é executar; se executar é mais do que decifrar; é mais do que mediar a obra apresentando-a ao público; se ler é executar e se executar é realizar a obra, isto é, levá-la à sua completude, isto é, deixando-a viver e fazendo-a viver de vida própria, do modo como ela se deixa, precisa e quer acontecer; se ler é executar e se executar é levar a obra a seu pleno acontecimento, isto, sem dúvida, 
diz respeito a todas as artes, também às ditas permanentes na tradição de conceito e arte, e não só as de som e palavra, mas também àquelas "visivas", nas quais o olhar não se limita a registrar passivamente, mas realmente executa, isto é, reconstrói a realidade vivente da obra, multiplicando as perspectivas e escolhendo os pontos de vista: relevos, tons, relações, contrastes, sombras e luzes, enfim, dirigindo, regulando e operando a "visão".

Ler a obra é, pois, executá-la. E executá-la, não se reduz à decifração.

Igualmente foi dito que a execução não se restringe ao, tantas vezes imporante, papel dos mediadores. Portanto, ler não se esgota nem em decifrar, nem em mediar a obra ao público. Ainda que no caso da mediação haja a presença muitas vezes decisiva dos mediadores que, no caso dos atores e dançarinos são até materiais secundário ${ }^{19}$ e fazem parte, de certa forma, da obra, desde a sua concepção, estão presentes já desde o seu ponto de partida, constituindo-se, de certo modo forte, em co-autores, não obstante, repito, a execução não se reduz à obra dos mediadores, porque não dispensa a execução que o espectador ou o ouvinte devem dar, por sua conta, se quiserem, de algum modo, aceder à obra.

Por isso, ver um drama no teatro ou ouvir um concerto no auditório não significa limitar-se a registrar passivamente o que está sendo apresentado, representado e interpretado, porque o ver e o ouvir pressupõem o olhar e o escutar, isto é, implica que se dê à obra que se olha e se escuta, uma execução própria, que a faça viver daquela vida que o espectador e o ouvinte presumem que seja a vida dela.

A obra só existe para mim se eu a executo.

Sendo assim, a execução do mediador não substitui a do espectador-ouvinte mas a facilita, enquanto está em condição de dirigi-la e de solicitar-lhe juizo. Isto é tanto assim que, quando o espectador e ouvinte querem julgar a execução do mediador, não têm outro critério senão a execução mesma que, para eles, coincide com a obra mesma.

Por isso, pode faltar a mediação, mas não pode faltar a execução. A obra, por assim dizer, está sempre num palco ideal: mesmo na leitura de uma peça teatral, na leitura de um romance, na leitura musical, na leitura da poesia. ${ }^{20}$

Mesmo que a execução interior fosse imperfeita e o executante fosse incapaz de exteriorizá-la, isto não mudaria a natureza das coisas.

Por isso, nenhuma obra de arte é em plenitude a não ser no momento efêmero de sua execução, de seu acontecimento, do seu momento explosivo de fogo de artifício. A existência artística de todas as obras depende desta momentânea efemeridade e, de certa forma, estão por ela sempre esperando.

Por fim, se ainda se perguntasse pelo fundamento deste essencial caráter de efêmera execução da obra de arte, talvez se devesse responder que a obra de arte requer execução porque ela nasce executada. Exigindo ser executada, a obra não

19 ALDRICH, Virgil C. Filosofia da arte. Rio de Janeiro: Zahar, 1969. p. 55-61.

20 "Autor implicito" e "leitor implicito" de W. Iser (The act of reading. A theorie of a esthetic response. Baltimore and London: The Johns Hopkins University Press, 1980, p. 29), referindo-se a Booth (1961), Fish (1970), Wolf (1971) e Riffaterre (1973). 
reclama nada que já não seja seu: ela é continente de si e esta é sua vida. Vida inventada e produzida e que quer sempre viver ainda. Inventada e produzida por um alguém em contexto e no entanto, desde o seu ponto de partida, com a exigência própria de um por-executar que é para si a sua própria lei. A obra, o homem artista a faz e, no entanto, ela mesma se faz. A execução, realizando a obra, pretende exatamente fazê-la viver desta sua vida, que é sua e somente sua.

Por isto, ler é executar e executar é fazer a obra ser, na sua realidade completa, e não só deixar a obra ser. A obra não tem outro modo de apresentar-se a não ser nesta execução do leitor. Só nesta atividade-receptividade do executor ou executante consegue a obra apresentar-se como ela é, o que significa dizer, o que ela dinamicamente quer ser.

A existência de qualquer obra de arte, portanto, tenha ela nascido dentro do contexto da adequação entre produção artística e conceito, seja ela provocação moderno-contemporâneo a qualquer tipo de tentativa de apropriação de seu ser pela razão dominadora, depende da efemeridade da execução que cada intérprete realiza e, neste momento de execução, ela subsiste.

Este ponto de vista, contrasta um pouco com o subseqüente a ser considerado no próximo item: aqui, a obra de arte não aparece como falha, incompleta, de algum modo insuficiente, e, só por isto, necessitante de execução. Aqui, na perspectiva pareysoniana, executar não significa nem completar, nem infundir nova vida. Não há metempsicose da obra. Mas significa fazer acontecer uma obra na sua plenitude, na plenitude de sua realidade semântico-sensivel, visiva ou sonora. Para Pareyson, o incompleto não pode ser executado, porque executar é fazer acontecer uma obra na sua plenitude e completude. Plenitude e completude que ela já possui, mas que reclama acontecer. Completar não é executar. Completar pressupõe insuficiência, executar pressupõe perfeição. Por isto, só o que é completo e vivente - semântico de significado próprio, tem a força de exigir execução. Perfeição, aqui, no sentido do particípio passado de "perficere", "per-acabado".

\section{5 - As lacunas da obra em processo de recepção}

"Toda obra de arte de qualquer espécie tem a caracteristica distintiva de não ser o tipo de coisa que é completamente determinada sob todos os aspectos pelas variedades de nível primário das suas qualidades, ou em outras palavras, contém em si lacunas características de definição, áreas de indeterminação: é uma criação esquemática. Ademais, nem todos os seus determinantes, componentes ou qualidades, estão em estado de realidade, mas alguns são apenas potenciais. Em conseqüência, uma obras de arte requer um agente que exista fora dela, isto é, um observador, a fim de - é a maneira como exprimo este fato - torná-la concreta. Por intermédio da sua atividade co-criativa na apreciação, o observador se põe, como comumente se diz, a 'interpretar' a obra ou, como prefiro dizer, a reconstrui-la em suas características efetivas, e, ao fazê-lo, por assim dizer sob a influência de sugestão que vem da obra de arte em si, completa sua estrutura esquemática, preenchendo, pelo menos em parte, as áreas de indeterminação e realizando vá- 
rios elementos que, por enquanto, estão apenas em estado de potencialidade. Deste modo se produz o que chamei de 'concreção' da obra de arte". ${ }^{21}$

Da citação de Ingarden, podemos depreender que, se a apreciação de uma obra consiste em trazer à percepção um objeto estético apropriado, no grau mais completo possivel, com base na "coisa" ou "acontecimento" material para o qual estamos atentando, então o processo de realização de uma obra é um processo de tornar definido ou concreto o que é indefinido.

Neste sentido se entende a afirmação de Merleau-Ponty de que "devemos reconhecer o indefinido como um fenômeno positivo". ${ }^{22} \mathrm{Se}$, ao contrário, tomarmos a percepção comum, quotidiana e ordinária como o nosso pseudo-definido, porque agarramos tudo com a neblina dos conceitos e práticas correntes, aí se entenderá a expressão de Osborne: "A percepção estética é um, processo de clarificação que torna o definido indefinido." 23

Aqui a palavra "realização" é usada em lugar da original actualization, derivada de to actualize que quer dizer realizar, efetivar, concretizar, converter em realidade, descrever com realismo. Daí, actual significando real, verdadeiro, autêntico, efetivo, objetivo, concreto. Portanto, trata-se de tomar atual, real, aquilo que é latente ou em potencial. E este é o processo de realização, ou de concreção.

A obra de arte aparece, então, como uma entidade que oferece uma possibilidade mais ou menos duradoura para que os intérpretes façam tais realizações ou concreções, com base numa "coisa material" ou numa série de "acontecimentos" que são o substrato existencial da obra de arte. ${ }^{24}$

Quando, dentro desta tradição, se diz que a obra de arte é um "objeto físico proposto como objeto estético", não se está afirmando a existência nem de dois objetos, nem de um segundo objeto esotérico. É um e o mesmo objeto que, porém, à presença de um observador preparado, se oferece em niveis de articulação e significado muito mais alto do que o corriqueiro. De fato, isto representa uma verdadeira mudança no objeto observado. Não se trata apenas de ver aspectos diferentes - aspecção - como acontece, por exemplo, nos jogos óticos ou de ilusão da percepção ótica; nem de projetar, de fora, qualquer coisa do tipo descobrir figuras nas formas das nuvens ou em manchas de umidade na parede. Trata-se, isto sim, de trazer à realização, o mesmo objeto comum que sempre desta forma se viu, mas com presença e significado estético, que sempre esteve ali, pelo menos como potencialidade, e que nunca houvera sido trazido à sua "concreção". Assim, o objeto físico se mostra como objeto estético.

Interessante se notar que o tempo de existência física do objeto artístico, neste caso, não determina o seu tempo de obra de arte. Este é determinado pela reciprocidade dialogal com a obra, pelo observador preparado, enquanto realiza desta forma a obra, atualizando-a. O tempo da obra de arte é então o tempo passadiço e efêmero da sua concreção no ato de ser apreciada ou interpretada. Seja a

21 INGARDEN, Roman. "Artistic and Aesthetic Values". In: British Journal of Aesthetics, 1964. In: OSBORNE, Harold. The art of appreciation. Oxford University Press, 1970. A apreciaçäo da arte. São Paulo: Cultrix, 1978. p. 287.

22. MERLEAU-PONTY, M. Phenomenology of perception. Trad. ingl. 1962, p. 6, $29,30$.

23

24

OSBORNE, H. Op. cit., p. 179-180.

OSBORNE, H. Op. cit., p. 180-181. 
obra moderna ou de qualquer época. Seja a obra duradoura na sua aparência física ou volúvel como um "fogo de artifício".

Requer-se, para que isto aconteça, no entanto, um observador preparado. Por isto, na perspectiva de Osborne, por exemplo, com pessoas que não estão preparadas para a apreciação estética, ao olharem um quadro, não se verifica nenhuma mudança deste tipo. "Elas vêem o quadro como uma representação - ele é para elas um campo de tal ou qual tamanho, com tantas vacas, tantas árvores, em tais ou quais relações espaciais uma com a outra, e assim por diante. [...] Nenhum objeto estético emerge. Tais pessoas não percebem que não conseguem tornar real um objeto estético. [...] É por isso que a discussão entre os que vêem e os que não vêem geralmente é inútil; sem o saberem, as duas partes estão falando de objetos visuais diferentes e incompativeis."25

Retornando a Roman Ingarden, encontramos a observação de que não há uma realização legítima única de uma obra de arte, nenhuma leitura "correta" única de um poema, ou da execução de uma peça musical, ou da maneira de ver um quadro. Há um sem número de realizações possíveis e legítimas. As "áreas de indeterminação" da obra podem ser preenchidas ou chamadas à sua concretude, ao seu ato, numa variedade de maneiras, todas elas válidas. "Toda obra de arte, de qualquer espécie, tem o traço distintivo de que não é a espécie de coisa que é completamente determinada sob todos os aspectos pelas variedades de nivel primário das suas qualidades, em outras palavras, contém em si lacunas características de definição, áreas de indeterminação: é uma criação esquemática". ${ }^{26}$

Está também suposta a possibilidade de realizações incorretas: violações que violentam a obra de arte. Tais distorções podem provir do modo incorreto de apreender características da obra, portanto, de falsas apreensões de aspectos da obra; modos de captar a obra que a forçam ou a distorcem; projeções, externalidades impostas à obra, que incorporam fantasias, imagens e associações do observador que não estão e não se fundam na obra mesma.

Por isto, continua Ingarden, "a toda obra de arte toca um número limitado de objetos estéticos possiveis [...] Falamos de possiveis objetos estéticos apenas nos casos em que as concreções de uma dada obra envolvem reconstruções fiéis dela, e também a maneira de equipar a obra e as realizações dos seus momentos de potencialidade ficam dentro dos limites indicados pelas suas qualidades efetivas. Estas concreções podem diferir entre si sob vários aspectos, porque uma obra de arte admite maneiras diversas pelas quais suas áreas de indeterminação podem ser ocupadas e concretizadas: algumas dessas maneiras de equipar se harmonizam melhor e algumas pior com os momentos plenamente articulados da obra e com o resto da implementação das suas indeterminações". ${ }^{27}$

Daí que toda obra de arte necessita de observadores competentes para consumar a realização e para emergir de suas próprias potencialidades. Assim que, não houvesse intérpretes - observadores competentes, a obra permaneceria des-

25 OSBORNE, H. Op. cit., p. 178.

26 OSBORNE, H. Op. cit., p. 188.

27 Id. ibid., p. 188. 
percebida ou não compreendida: num sentido muito verdadeiro, ela não se tornaria real.

Portanto, também por este ponto de vista, se evidencia o caráter efêmero da obra de arte. Não se apresentando a obra como uma coisa em si e para si; ela existe, em realidade, quando "arrancada da sua monotonia e vulgaridade", ${ }^{28}$ ou quando e enquanto encontra sua realização, sua concreção, na leitura do intérprete.

Esta leitura interpretante, sem dúvida, está sempre sob a injunção das variáveis pessoais do gosto, das flutuações sociais: da historicidade. A propósito, Ingarden se manifesta: "O aparecimento de possiveis concreções de uma obra de arte obviamente depende, não apenas da obra mesma, senão também da presença de observadores competentes e de ser ela apreendida por eles de um modo em vez de outro. Isto, por sua vez, depende de diversas condições históricas. Por isso, qualquer obra de arte (e isto funciona de modo diferente para as diversas artes) passa por vários periodos de brilho, isto é, periodos em que atrai freqüentes e corretas concreções estéticas, e outros periodos em que sua atracão é enfraquecida ou mesmo desaparece se já não é "legivel" para o seu público. Ou, ainda, pode se deparar com observadores que têm uma maneira completamente diferente de reagir emocionalmente, que se tornaram insensiveis a certos valores da obra ou francamente hostis a eles, e que, portanto, não estão qualificados para produzir o tipo de concreção em que estes valores brilham e atuam sobre o observador. Quando isto acontece, a obra de arte é não só ilegivel, mas é como se fosse muda" ${ }^{29}$ É de se dizer, como se não fosse, como se não tivesse existência.

Ingarden (1965), coetâneo do estruturalismo checo, entende, pois, a obra de arte como multiestratificada, abrindo perspectivas para o esclarecimento das condições em que a obra se torna comunicativa. $O$ inacabamento essencial do objeto artístico, apontado nas "zonas de indeterminação" que estão latentes nas objetividades apresentadas, chama por um "leitor" dinâmico, propõe-lhe uma ação concretizadora e leva o "leitor", de estrato em estrato, ao possivel sentido da obra.

Com a Escola de Constrnça, na Alemanha, a partir dos anos 60, sob o nome de "estética da recepçêrr afirma uma modificação do âmbito e do comportamento, sobretudo na arle literária, quando se inclui o termo "público", a reação do público à obra. Reconhecendo a potência semântica da obra e o fato de que ela se evidencia e se torna comunicável através da reação do público, se tentou articular as informações da lingüística sobre a estrutura verbal, com as da psicologia e as da sociologia, sobre as condições psíquicas e materiais de produção e de recepção: um modelo, enfim, que tentasse explicar a forma da recepção como função, no caso, da forma do texto. ${ }^{30}$ A proposta é divulgada pela palavra de Jauss, ${ }^{31} \mathrm{em}$ aula inaugural da Universidade de Constança, em 1967, com a apresentação das

\footnotetext{
28 HEIDEGGER, M. Caminos de bosque. Madnid: Alianza, 1995.

29 In OSBORNE, H. Op. cit., p. 191.

30 GUMBRECHT, H. U. et al. Prisentación de la situación de la "Literaturwissenschaft" alemana: análisis y perspectivas. - Li astual ciencia literaria alemana. Seis estudios sobre el texto y su ambiente. Salamanca: Anaya, 1971, p. 22

31 Op. cit., p 37-114.
} 
conhecidas sete teses, lançadas como base a uma renovação da historiografia literária. Ponhamos em relevo, para o que nos interessa, as teses 1, 2, 3 e 5.

1. A partir do contato vivo da obra literária com seus leitores e da concepção de que o historiador, antes de mais nada, tenha de adotar a função de leitor para que possa "fundamentar seu juizo porque conhece seu lugar na sucessão histórica dos leitores" 32

2. Pela concepção de "horizonte de expectativas", determinável "pela tradição do seu gênero, pela forma e matéria das obras anteriores mais conhecidas e pela oposição entre a linguagem poética e a prática". ${ }^{33}$

3. Pelo parâmetro que esse horizonte traz para a avaliação do caráter artístico de uma obra, no confronto de expectativas do público e a forma concreta do objeto, que se materializa "na variedade das reações do público e dos juizos da crítica (êxito espontâneo, desprezo, inovação, aprovação esporádica, compreensão cada vez mais crescente ou tardia, etc.)" ${ }^{34}$

5. Pela interação dinâmica da recepção ativa com a produção, gerando o desenvolvimento das obras que precisam continuar fornecendo respostas aos problemas formais e morais ainda em aberto e propondo novas questões. ${ }^{35}$

Segundo Gumbrecht, no início discípulo de Jauss em Constança, a Estética da Recepção não se ocupa apenas com o registro das mudanças detectáveis no presente, mas procura ter em consideração a possibilidade infindável de alterações que vão fazer parte, no tempo, da significação da obra, através da seqüência de recepções da mesma obra, no tempo. $\mathrm{O}$ fato artístico, aparece assim, como necessariamente inexato na sua representação real e com potencial semântico. A categoria "futuro" passa a fazer parte da constituição da obra, porque esta está entregue a uma trajetória histórica de recepção.

Por fim, com a teoria do efeito estético proposta por W. Iser, também dentro da Escola de Constança, que leva em consideração o diagrama de Dällenbach ${ }^{36}$ as interações reciprocas e concomitantes entre (1) Sujeito e Processo de Produção/ (2) Texto/ (3) Sujeito e Processo de Recepção/ (4) Contexto Histórico, Inconsciente - o texto literário se revela não como uma cópia do mundo representado, nem discurso críptico verbal carregado de um significado único, ocultado na rede dos símbolos e passivel de ser atingido unanimemente por um ou mais exegetas atilados, mas sim com uma natureza bipolar de objeto artístico (o texto material lingüístico e gráfico) e. de objeto estético (sua concretização pelo recebedor). A obra, no entanto, não se identifica, em nenhum momento, com qualquer uma destas dimensões se tomadas como totalidades separadas, mas, ao contrário, só se faz perceptivel a partir da interação de ambas as dimensões.

$\mathrm{E}$ aqui nos deparamos, outra vez, com o objeto de nosso propósito neste estudo: há uma instabilidade da obra que se deve à constante interrupção do processo lógico de produção do sentido, face às zonas de indeterminação que, agora, am-

32

33

34

35

36

Op. cit., p. 70-71.

Op. cit., p. 74.

Op. cit., p. 77.

Op. cit., p. 91-92.

DÄLLENBACH, L. "Actualité de la recherche allemande". In: Poétique 39. Paris: Seuil, 1979, p. 260. 
pliadamente, circundam os seres, ambientes e fatos imaginários, obrigando o leitor a uma participação efetiva na mediação das perspectivas propostas pelo autor. E essa mediação não se traduz em algo preestabelecido no texto, na obra, mas no que nasce da capacidade ideativa e imaginativa de quem o (a) atualiza. ${ }^{37}$ " [... 0 leitor, ao correr das transformações a que o levam os signos do texto, produz seu objeto imaginário e paralelamente manifesta a necessidade incontornável de um texto de ser constituido por uma consciência: aquele, em sua facticidade, é uma pura virtualidade; sua atualidade pode apenas ser encontrada nessa consciência. Disso se deduz que o texto de ficção deva ser considerado, antes de tudo, como uma comunicação, e o ato de leitura, como uma relação dialógica." 38

O que se afirma da obra ficção é perfeitamente aplicável a qualquer obra, uma vez que, com o particípio passado de fingere, toda a produção artistica pode ser qualificada. Não era por outra razão que, até pelo menos o século $\mathrm{V}$, pintores costumavam assinar seus quadros apondo um "fulano de tal finxit na tela", "fulano de tal construiu inventivamente com a mente (imaginação)".

Aqui se constata forte influência da teoria dos atos de fala - speech-act theory - de J. Austin, ${ }^{39}$ retomada por J. Searle, e da concepção já aludida de Ingarden (1931) sobre a polifonia e as zonas de indeterminação da obra de arte. Há sentidos que passam a existir só quando se desencadeia o processo da comunicação. E quanto às indeterminações, passam a ser "vazios", "lacunas", "indices de relações potenciais", para Iser.

Expandindo a concepção de Ingarden sobre os pontos de indeterminação, constitutivos da obra, Iser esclarece: "Agora estamos em condições de definir mais precisamente o que se quer dizer com a participação do leitor. Se as lacunas são relevantes para que se produzam os atos de concretização, então o papel do leitor não é apenas o de 'internalizar' posições fixadas no texto, mas o de agir sobre elas criativamente, provocando, com isso, o surgimento do objeto estéti$\mathrm{CO}$. 40

"Provocando, com isso, o surgimento do objeto estético".

Concluo, afirmando a inconsistência de se considerar o produto artístico ou como um fato concluido e definido na sua própria constituição de objeto físico; ou como um resultado intencional exitoso, o que Aldrich denomina de falácia intencionalista; ou como um objeto desde sempre explicável pelo aparato teórico, filosófico ou de qualquer outra ordem - falácia essencialista; ou de algo passivel de apropriação ideológica - coisa de mercado, instrumento ou meio de uso para; mas, concluo, que, qualquer que seja o objeto artístico, independente de sua época de surgimento - embora a ela sempre referenciado -, independente do seu autor -

37 Cfr. ISER, W. The implied reader; patterns of communication in prose fiction from Bunyam to Beckett. Baltimore and London: The Johns Hopkins University Press, 1978. p. 277. Der Implizite Leser: Kommunikationsformen des Romans von Bunyam bis Beckett. München, 1972. Der Akt des Lesens. Theorie ästhetischer Wirkung.

38 ISER, W. "La fiction en effet". In Poétique 39. Paris: Seuil, 1979, p. 279.

39 AUSTIN, J. L. How to do things with words. London, Oxford, New York: Oxford University Press, 1976. SEARLE, J. R. Les actes de langage. Essai de Philosophie du langage. Paris: Hermann, 1972.

40 ISER, W. The act of reading. A theorie of a esthetic response. Baltimore and London: The Johns Hopkins University Press, 1980, p. 203. 
embora a ele sempre referenciado, independente da sociedade - embora a ela sempre referenciado, existe enquanto objeto estético na momentaneidade efêmera da relação com o seu outro que é o leitor, o espectador, o fruidor, o "crítico", o dialogador, o participador, o intérprete: aquele que, em a deixando ser, faz com que a obra, ela mesma, seja; seja das infindas possibilidades de ser que a obra mesma traz consigo e que as suscita todas. Por isto, seja a obra dita de qualquer época, seja a arte dita moderna, ela só encontra existência na execução que a realiza, a concretiza e a atualiza, sempre inovadamente de novo: na execução do intérprete, dentro do processo de interpretação. Este é o caráter efêmero de toda a obra de arte ou a efemeridade do que é permanente na obra artística: o seu renovado acontecer no tempo. Sua vida, que é dela, está entregue às suas execuções e leituras. E aí, nelas só, vive. Neste efêmero instante.

\section{Referências bibliográficas}

ADORNO, Theodor W. Teoria estética. São Paulo: Martins Fontes, 1970.

ALDRICH, Virgil C. Filosofia da arte. Rio de Janeiro: Zahar, 1969.

AUGUSTO, Maria Helena Oliva. Tempo Social - Revista de Sociologia da USP, v. 6 n. 1 e 2, jun. 1995 -

Artigo "O moderno e o contemporâneo: reflexōes sobre os conceitos de individuo, tempo e morte".

AUSTIN, J. L. How to do things with words. London, Oxford, New York: Oxford University Press, 1976.

CROCE, Benedetto, Breviario de estetica, 6. ed. Buenos Aires: Espasa Calpe, 1947.

DÄLLENBACH, L. Actualité de la recherche allemande. In: Poétique 39. Paris: Seuil, 1979.

ECO, Umberto. Obra aberta. 2. ed. São Paulo: Perspectiva, 1971.

FOCLLON. Vie des formes. Paris: Presses Universitaires de France, 1947.

GUICHARD-MEIL, Jean. Cómo mirar la pintura. 3. ed. Barcelona: Labor, 1968.

GUMBRECHT, $H$. U. et al. Presentación de la situación de la "Literaturwissenschaft" alemana: análisis

y perspectivas. - La actual ciencia literaria alemana. Seis estudios sobre el texto y su ambiente.

Salamanca: Anaya, 1971.

HEGEL, Georg Wilhelm F. Estética. Lisboa: Lisboa Guimarães, 1962, 1964, 1972, 1993.

- Aesthetik. Frankfurt: Ed. Gmbh, 1960.

—. Einleitung in die Aesthetik. München: W. Fink, 1967.

- Poética. Buenos Aires: Espasa Calpe, 1947.

HEIDEGGER, Martín. A ongem da obra de arte. Lisboa: Edides 70, 1992.

- Caminos de bosque. Madrid: Alianza, 1995.

HERRERO, David Estrada. Estetica. Barcelona: Herder, 1988.

HORKHEIMER, Max. Eclipse da razão. Rio de Janeiro: Labor, 1976.

INGARDEN, Roman. A obra de arte literánia. Lisboa. Calouste Gulbenkian, 1965.

- Artistic and aesthetic values. In: British Journal of Aesthetics, 1964. In: OSBORNE, Harold.

The art of appreciation. Oxford University Press, 1970. A Apreciação da Arte. Säo Paulo: Cultrix, 1978.

ISER, W. La fiction en effet. In: Poétique 39. Paris: Seuil, 1979.

- The act of reading. A theorie of a esthetic response. Baltimore, London: The Johns Hopkins University Press, 1980.

- The implied reader; patterns of communication in prose fiction from Bunyam to Beckett.

Baltimore, London: The Johns Hopkins University Press, 1978, p. 277. Der Implizite Leser: Kommunikationsformen des Romans von Bunyam bis Beckett. München, 1972. Der Akt des Lesens. Theorie ästhetischer Wirkung.

JAUSS, H. R. La historia literaria como desafio a la ciencia literaria. In: GUMBRECHT, H. U. et al. La actual ciencia literaria alemana; seis estudios sobre el texto y su ambiente. Salamanca: Anaya, 1971.

LIPOVETSKI, Gilles. La era del vacio. Barcelona: Anagrama, 1988. 
MARCUSE, H. L'homme unidimensionnel. Paris: Minuit, 1968.

MAYZ VALLENILLA, E. El dominio de poder. Barcelona: Ariel, 1982. Esbozo para una crítica de la razón técnica. Caracas: Monte Avila, 1974.

MERLEAU-PONTY, M. Phenomenology of perception. Trad. ingl. 1962.

- A dúvida de Cézanne - O olho e o espírito. In: São Paulo: Abril Cultural, 1975. (Os Pensadores)

NETTO, J. Teixeira Coelho. Introduçāo à teoria da informaçăo estética. Petrópolis: Vozes, 1973.

OSBORNE, Harold. Estética e teoria da arte. 2. ed. São Paulo: Cultrix, 1974. . A apreciação da arte. São Paulo: Cultrix, 1978.

PAREYSON, L. Conversazioni di estetica. Milano: U. Mursia \& C., 1966.

- Os problemas da estética. São Paulo: Martins Fontes, 1985.

- L'estetica di Kant. Milano: U. Mursia \& C., 1968.

- Verità e interpretazione. 2. ed. Milano: U. Mursia \& C., 1972.

- Luigi. Estetica: teoria della formatività. 3. ed. Firenze: G. C. Sansoni S.p.A., 1974. (Prima Edizione - Torino: Biblioteca di Filosofia, 1954)

- Estética, teoria da formatividade. Petrópolis: Vozes, 1993.

PAVIANI, Jayme. A arte na era da indústria cultural. Porto Alegre: PyR, 1987.

- Estética mínima: notas sobre arte e literatura. Porto Alegre: EDIPUCRS, 1996.

QUADROS, Odone José de. Estética da vida, da arte, da natureza. 2. ed. Porto Alegre: Acadêmica, 1986.

— A linguagem da arte. Letras Hoje, Porto Alegre, EDIPUCRS, n. 8 e 9, dez. 1991.

. O personalismo ontológico em Luigi Pareyson, Veritas, Porto Alegre, EDIPUCRS, v. 36, n. 142 , jun. 1991, p. 191-208.

SAFT, Emi Maria Santini. Funçöes, recepção e efeito estético dos textos literários. Porto Alegre: Dissertação de Mestrado, PUCRS/LA, 1983.

SEARLE, J. R. Les actes de langage. Essai de Philosophie du langage. Paris: Hermann, 1972.

TIBURI, Márcia. Crítica da razão e mímesis no pensamento de Theodor W. Adomo. Porto Alegre: EDIPUCRS, 1995. 